\title{
Dynamic Response of the Pre-load Steel Frame Under Transverse Impact
}

\author{
Mianyue Yang ${ }^{1}$ and Chaojiang $\mathrm{Fu}^{1,2, *}$ \\ ${ }^{1}$ School of Civil Engineering, Fujian University of Technology, Fuzhou 350118, China \\ ${ }^{2}$ Fujian Provincial Key Laboratory of Advanced Technology and Informationization in Civil Engineering, Fuzhou, 350118, China \\ ${ }^{*}$ Corresponding author
}

\begin{abstract}
The process of dynamic response for the pre-load steel frame subjected to impulsive load is a complicated nonlinear problem. In this paper, the ABAQUS nonlinear finite element analysis software is used to simulate the dynamic response of the pre- load steel frame subjected to transverse impact loading. The parametric study shows that: the increasing of impact kinetic energy and impact location will increase the dynamic response of the steel frame; the dynamic response is primarily dependent on the level of impact kinetic energy; at the same impact kinetic energy, a smaller impacting velocity with a higher mass tends to give more severe dynamic response of the pre- load steel frame.
\end{abstract}

Keywords-dynamic response; transverse impact; steel frame; nonlinear finite analysis; simulation

\section{INTRODUCTION}

With recent advance in structural engineering and material sciences, modern buildings become increasingly larger and taller. However, these structures are threatened by abnormal loads due to accidents, faulty practice, terrorist attacks, etc. As early as 40 years ago, Leyendecker et al. [1,2] indicated the probability of occurrence of abnormal loads, and the building destroyed by abnormal loads due to accidents had happened many times. Especially in the "9.11" terrorist attacks, engineers realized the importance of structural resistance to abnormal loads and had put more efforts to the impact resistance of structures.

At present, the research on the impact resistance of structures is mostly based on lateral impact loading and without considering the pre-load situation. Sawamoto [3] proposed a new analytical approach for assessing local damage to reinforced concrete structures subjected to impact load by applying the discrete element method (DEM). Through the large-scale structural impact test and the information about the ruins of the building after the 9.11 incident, Albolhassan [4] has analyzed the response of the overall structure for the first time, and put forward protective measures. Lynn [5] analyzed the dynamic response of the structure subjected to impact load. The paper pointed out that the impact of the impact mass is greater than the impact velocity. Xiong [6] proposed the critical condition of collapse and the corresponding protective methods when impact load was acted on the steel frame with composite slab and provided a guide for the research on the collapse of structure.

Based on the above reasons, The ABAQUS is used to carry on a large number of parameters on the dynamic response of pre-load steel frame model under transverse impact loading.
The concept of the critical impact energy is presented, which is used to the judging criterion of structural failure in this paper.

\section{FinITE ELEMENT MODELLING AND VALIDATION}

\section{A. FE Model}

ABAQUS is employed to conduct three-dimensional nonlinear dynamic simulation. ABAQUS is a general purpose finite element software in which the main solution methodology is based on explicit time integration. Thus, numerical convergence difficulties in implicit methods can be avoided. This solver is beneficial to solving complex nonlinear problems, such as contact, large deformations and material fracture.

The steel frame model is $4800 \mathrm{~mm}$ in height and $7800 \mathrm{~mm}$ in span. The size of the steel frame can meet the requirements of the 8-storey student apartment [7]. The frame model is shown in Figure I, and the section size of the frame beam column is shown in Table I. The $q$ represents the load on which the plate passes to the beam, with a value of $50.7 \mathrm{kN} / \mathrm{m}$. $F$ represents the axial compressive load, and the value is $50 \%$ of design axial compressive load of the frame. In this paper, the impact side column is R column, and the other column is $\mathrm{L}$ column.

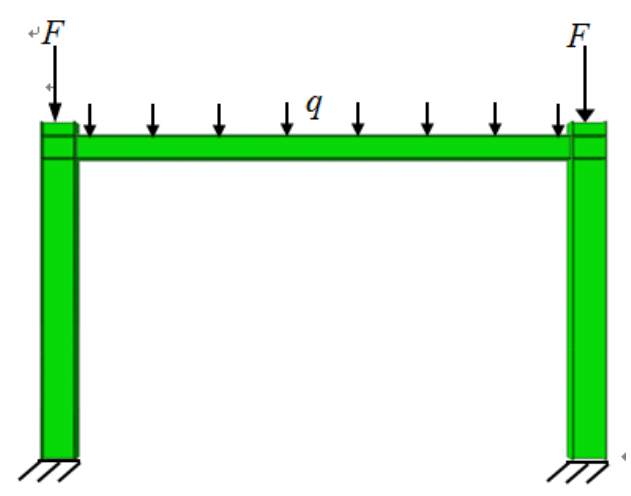

FIGURE I. $\quad$ MODE OF STEEL FRAME

TABLE I. SECTION SIZE OF FRAME COLUMN AND BEAM

\begin{tabular}{|c|c|}
\hline Size of column ( $\mathbf{m m})$ & Size of beam $(\mathbf{m m})$ \\
\hline $\mathrm{H} 500 \times 400 \times 12 \times 16$ & $\mathrm{H} 350 \times 350 \times 10 \times 16$ \\
\hline
\end{tabular}

The impactor was assumed to be rigid mass with a cubic section of a dimensions $(400 \times 500 \times 1500) \mathrm{mm}$ as shown in Figure II. Mass of impact mass can be changed by adjusting 
the mass density. The impact mass moves only in the direction of velocity and impacts the steel frame along the column's strong axis.

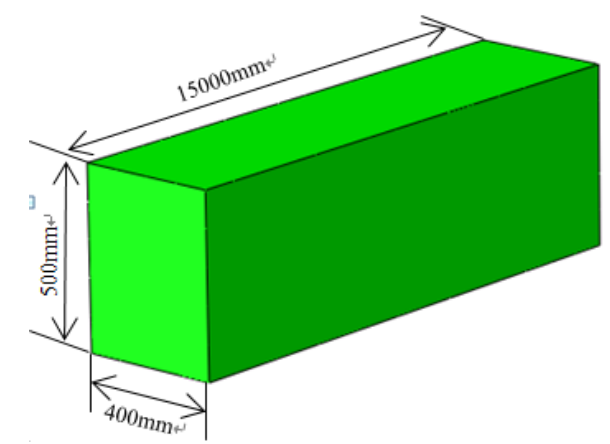

FIGURE II.

SHAPE AND DIMENSIONS OF THE IMPACTOR

\section{B. Constitutive Model of Material}

The steel frame is modeled as a Johnson-Cook, elasticplastic material with a Young's modulus of 200GPa, a Poisson's ratio of 0.3 , and a density of $7800 \mathrm{~kg} / \mathrm{m}^{3}$. The Johnson-Cook model is appropriate for modeling high-rate impacts involving metals. The Johnson-Cook model is expressed in Eq. (1).

$$
\sigma_{\text {eq }}=\left[A+B\left(\varepsilon_{\text {eq }}\right)^{n}\right]\left[1+C \ln \left(\frac{\dot{\varepsilon}_{\text {eq }}^{p}}{\dot{\varepsilon}_{0}}\right)\right]\left[1-\theta^{m}\right]
$$

Where $\sigma_{\text {eq }}$ is yield stress, $\varepsilon_{\text {eq }}$ is the equivalent plastic strain, $A, B, n, m$ and $C$ are material parameters, $\theta$ is the nondimensional temperature, $\dot{\varepsilon}_{\text {eq }}^{p}$ is the equivalent plastic strain rate, $\dot{\varepsilon}_{0}$ is reference strain rate.

The Johnson-Cook material parameters are taken from Lin $\mathrm{Li}$ [8] in which the following constants are used: $A=244.8 \mathrm{MPa}$, $B=899.7 \mathrm{MPa}, C=0.0391, m=0.757, n=0.94$, and $\dot{\varepsilon}_{0}=0.000833$ $\mathrm{s}^{-1}$. Furthermore, the melting temperature is $1795 \mathrm{~K}$, and the transition temperature is $293 \mathrm{~K}$.

\section{Validation}

In the paper, it is found that a fine mesh of $15 \mathrm{~mm}$ element size provides adequate accuracy and minimum computational time in modeling the nonlinear deformation in the regions of impact, whereas, a coarse mesh of $60 \mathrm{~mm}$ element size is used elsewhere.

It is an important method of analyzing the rationality of numerical simulation results to check whether the energy of the system is reasonable, whether the relationship of energy transformation is correct and whether the hourglass energy can be effectively controlled [9]. Figure III shows the system energy curve during impact. AllKE is kinetic energy for whole model, ALLIE is internal energy for whole model, ALLAE is hourglass energy for whole model, and ALLWK is external work for whole model. It can be seen from Figure III that the impact energy is converted into internal energy, system kinetic energy and hourglass energy during the impact process. The work done by external force is transformed into internal energy of the system. The whole process is conservation of energy. Figure IV shows the ratio of the hourglass energy to the total energy and the ratio of the hourglass energy to the internal energy during impact process. As can be seen from Figure IV, the hourglass energy is within $10 \%$ of the total energy and internal energy. It is shown that the calculation results are reliable[10].

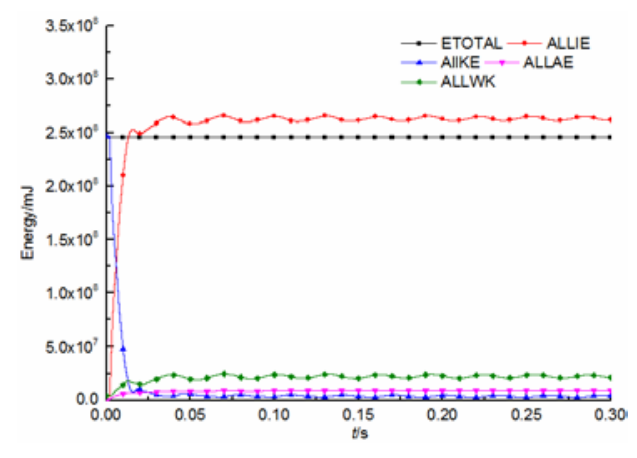

FIGURE III. SYSTEM ENERGY CURVES

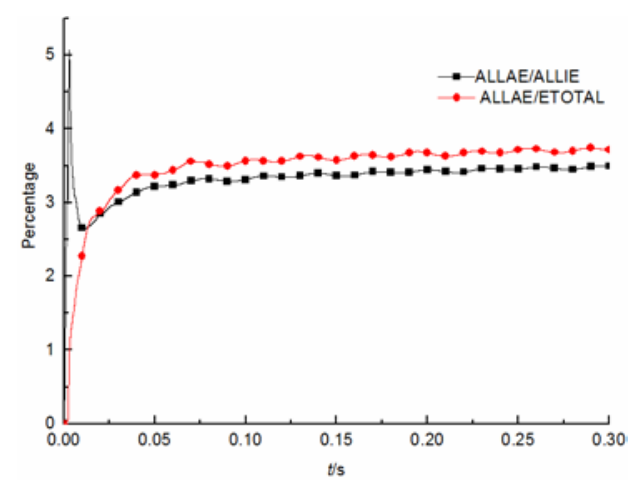

FIGURE IV.

ALLAE/ALLIE AND ALLAE/ETOTAL CURVES

\section{ANALYSIS RESULTS}

In real life, the impact mass and velocity cannot be predicted. Therefore, it is difficult to reflect the response and change of steel frame under transverse impact load by using a set of impact parameters alone. In this paper, the analysis parameters include the impact velocity $V$, the impact mass $T$, the impact position $L$. In this paper, $1 \mathrm{~T} 69 \mathrm{~V} 1 \mathrm{~L}$ represents the impact mass of $1 \mathrm{t}$, the impact velocity of $69 \mathrm{~km} / \mathrm{h}$, the impact of the position of $1 \mathrm{~m}$, and so on.

\section{A. Impact Energy}

The most simplistic analytical method for the steel frame subjected to transverse impact loads will be to assume quasistatic behavior. This approach is based on the energy balance principle and the most important parameter for the impactor is its kinetic energy. To investigate this assumption, the numerical simulations are considered a constant level of impact energy but different combinations of impacting mass 
and velocity. Figure V and VI present the different displacement histories of the steel frame for the same level of impact kinetic energy.

It can be notice from Figure V and VI that the deformation of the steel frame under the same level of external impact energy but with different combinations of impact mass and velocity are different. Both Figures indicate that a smaller velocity with a higher mass tends to give more severe structure response.

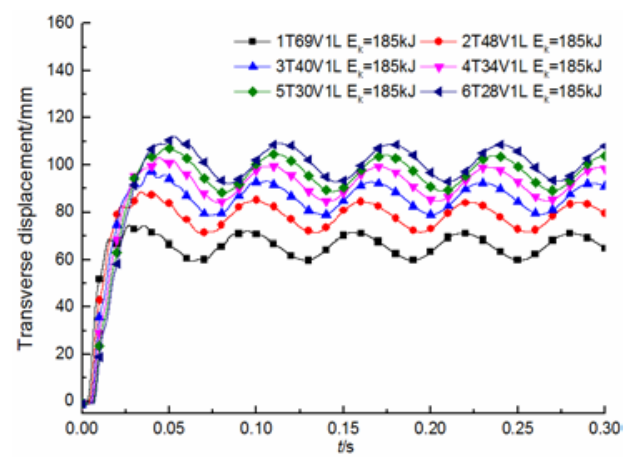

FIGURE V. TRANSVERSE DISPLACEMENT-HISTORY CURVES AT MIDDLE OF THE L COLUMN UNDER THE SAME IMPACT ENERGY

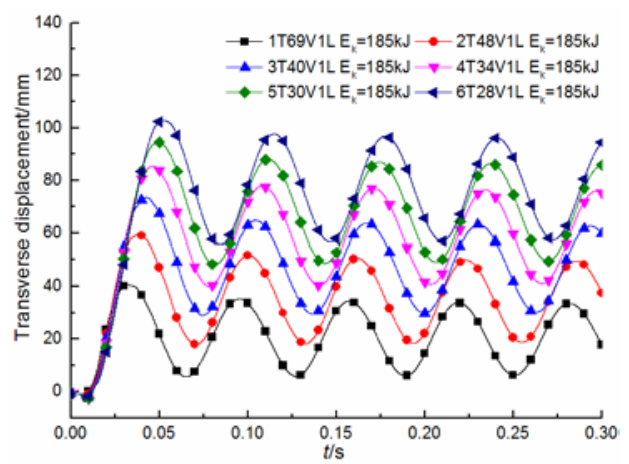

FIGURE VI. TRANSVERSE DISPLACEMENT-HISTORY CURVES AT TOP OF THE R COLUMN UNDER THE SAME IMPACT ENERGY

It can be seen in the Figure VII, with the increasing of impact energy, the axial displacement at top of the $\mathrm{L}$ column is more and more large. When the impact kinetic energy is large enough, the axial displacement of the column top tends to be infinite. The steel frame is failed.

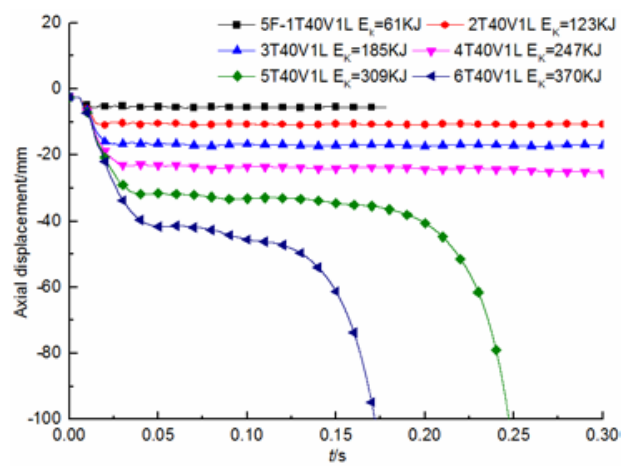

FIGURE VII. AXIAL DISPLACEMENT-HISTORY CURVES AT TOP OF THE L COLUMN UNDER DIFFERENT IMPACT ENERGY
After impact, if the frame is stable, the kinetic energy of the system will become zero when both the frame and the impactor come to rest. In contrast, if the frame fails after impact, then the frame will accelerate in deformation and the kinetic energy will increase. The energy histories of these different situations are exemplified in Figure VII.

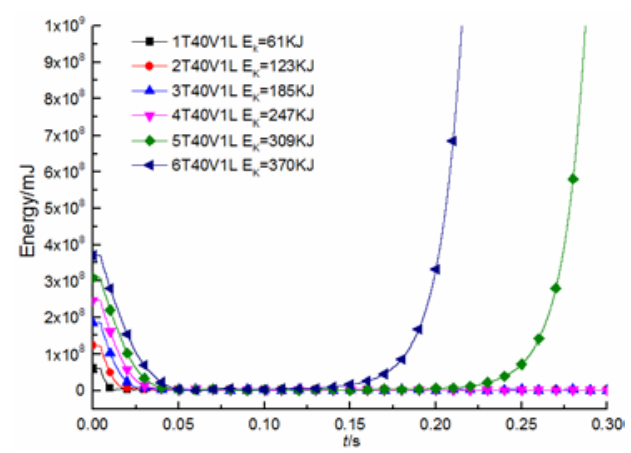

FIGURE VIII. TOTAL KINETIC ENERGY HISTORY OF THE SYSTEM UNDER DIFFERENT IMPACT ENERGY

\section{B. Impact Location}

The effect of impact load is examined at three different locations along the steel column; at $1 \mathrm{~m}, 1.5 \mathrm{~m}$ and $2 \mathrm{~m}$ from the bottom support. This can be explained by the fact that the column might be subjected to impact with vehicles of different heights.

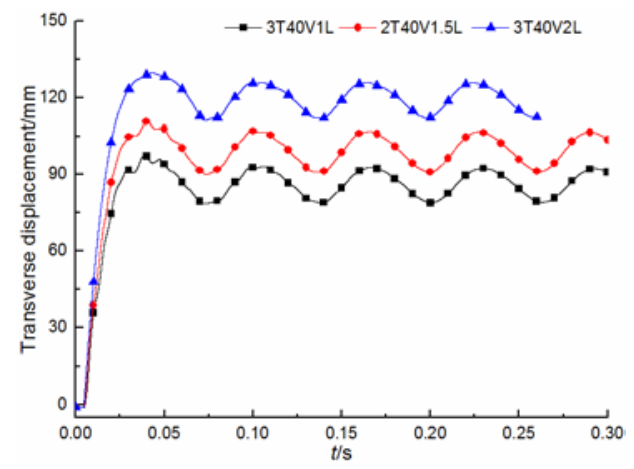

FIGURE IX. TRANSVERSE DISPLACEMENT-HISTORY CURVES AT MIDDLE OF THE L COLUMN UNDER DIFFERENT IMPACT LOCATIOM

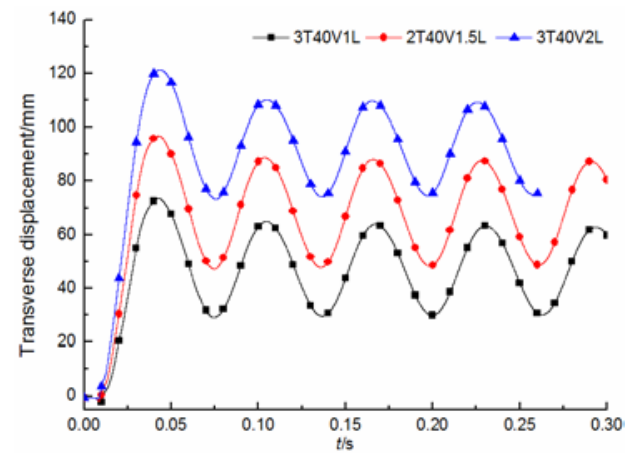

FIGURE X. TRANSVERSE DISPLACEMENT-HISTORY CURVES AT TOP OF THE R COLUMN UNDER DIFFERENT IMPACT LOCATION 
The influences of impact location on the behavior of impacted frame have shown in Figure IX and X. The impact location has a noticeable effect on the dynamic behavior of the steel frame. Figure IX exhibits minor changes of transverse displacement at middle of the $\mathrm{L}$ column with the increase of impact location. Figure $\mathrm{X}$ shows that a higher impact location tends to give a lager transverse displacement. Figure IX and X indicate that a higher location tends to give more severe structure response.

\section{SUMmARY AND CONCLUSIONS}

This paper focuses on the dynamic response of the pre-load steel frame under transverse impact load. Explicit dynamic solver in ABAQUS is employed to conduct numerical simulations. The FE model is validated by checking the transformation of energy and the ratio of hourglass energy. Based on the validated FE model, parametric studies are conducted to investigate the effects of various parameters on the dynamic response. Conclusions are drawn from numerical simulations as follows:

- The impact energy is a key parameter on the displacement response of the pre-load steel frame subjected to a transverse impact load. Increasing the impact energy will increase the dynamic behavior of the steel frame.

- A smaller velocity with a higher mass tends to give more severe structure response at the same level of impact energy.

- Impact location has significant influence on the dynamic response. A higher impact location tends to give a more severe structure response.

\section{ACKNOWLEDGMENT}

The authors gratefully acknowledge financial support by National Natural Science Foundation of China (No. 51378124).

\section{REFERENCES}

[1] E. V. Leyendecker, E.F.P. Burnett, The lncidence of Abnormal Loading in Residential Building, NBS Building Science Series, NO. 89, National Washington, DC, 1976.

[2] E. V. Leyendecker, B. R. Ellingwood, "Design Methods for Reducing the Risk of Progressive Collapse in Buliding," NBS Building Science Series NO. 89, National Washington, DC, 1977.

[3] Y. Sawamoto, “Analytical studies on local damage to reinforced concrete structures under impact loading by discrete element method," Nuclear Engineering and Design, 1998, vol. 2, pp. 157-177.

[4] A. Astaneh-Asl, Progressive collapse prevention in new and existing buildings. Proc. of the 9th Arab Structural Engineering Conf, 2003, vol. 9: pp. 253-359.

[5] K. M. Lynn, D. Isobe, "Structural collapse analysis of framed structures under impact loads using ASI-Gauss finite element method," International Journal of Impact Engineering, 2007, vol. 9, pp. 15001516.

[6] Xiong Shishu, Pan Qincun and Xiong Mingxiang, "The Collapsed Analysis and Study of Protective Methods of Steel Frame with Composite Slab uunder Impact Load,” Journal of Railway Engineering Society, 2006, NO. 8, pp. 53-57.

[7] Chen Hong, Yang Lu, "Comparision analysis on slasto-plastic time history of multi-layer steel frame structure with multi-directional seismic waves,” Journal of Natural Science of Heilongjiang University, 2016, Vol. 33, pp.405-409.
[8] Lin Li, Zhi Xudong and Fan Feng, et al. "Determination of parameters of Johnson-Cook models of Q235B steel,” Journal of vibration and shock, 2014, Vol. 33, pp.153-158.

[9] Zeng Pan, Nonlinear analysis principle of plasticity, Beijing, China Machine Press, 2015.

[10] Bai Jinze, Theoretical Basis and Case Analysis of LS - DYNA3D, Beijing, Science Press, 2005. 